\title{
O grupo de sociedades: mecanismo de inserção da empresa transnacional na nova ordem econômica internacional*
}

\section{A group of societies: the transnational business insertion means in the new international economic order}

Daniel Amin Ferraz ${ }^{1}$

\section{Resumo}

O mundo atual é o mundo dos grupos de sociedades. Hoje em dia, é o grupo de sociedades entendido como um instrumento de concentração de terceira geração, permitindo a concentração na unidade econômica e na multiplicidade jurídica. Assim, distintas personalidades jurídicas atuarão sob o mesmo controle econômico e de gestão, de forma coletiva no mercado, correspondendo à expectativa de larga escala de produção, distribuição e inovação. Assim, o Direito, por meio de um Meta-Direito, o direito do grupo de sociedades, dotou os empresários coletivos de um instrumento que lhes permita atuar no mercado global.

Palavras-chave: Grupos de sociedades. Instrumento de concentração. Controle econômico. Mercado global.

\begin{abstract}
The actual world is the world of corporate groups. This is what we understand, nowadays, as the instrument of concentration of third generation, which will enable the economic unit and the legal multiplicity: different legal personalities under economic and single management control will operate in a collectively way in the market, corresponding to the expectation of large-scale production, distribution and innovation. Thus, the Law, through a Meta-Law, the rights of corporate groups, has given to the collective employers an instrument that allows them to act in the global market.
\end{abstract}

Keywords: Corporate groups. Instrument of concentration. Economic control. Global market.

* Artigo recebido em 14/10/2011 Aprovado em 05/11/2011

Mestre em Direito Empresarial pela Universidade de Coimbra, Portugal; Doutor em Direito Empresarial Internacional pela Universidad de València, Espanha; Professor do Mestrado/ Doutorado do UniCeub - Centro Universitário de Brasília; Advogado, titular de Amin, Ferraz Coelho Advogados Associados; Email: daniel. amin@afcadvogados.adv.br 


\section{Aproximação da matéria}

\subsection{Acepção restritiva e ampla}

Os grupos de sociedades desempenham, nas circunstâncias atuais, um papel essencial no movimento geral das concentrações empresariais ${ }^{2},{ }^{3}$.

Es sabido que el concepto de grupo de sociedades sirve para describir la empresa pluri corporativa: coexistencia de los fenómenos pluridad de entidades jurídicamente independientes y unidad empresarial subyacente. Normalmente, la vertebración de la unidad empresarial se manifiesta en relaciones de dependencia/subordinación entre las entidades vinculadas: la unidad de dirección se hace efectiva mediante el ejercicio de un poder de dirección legítimo, cualquiera sea su causa, de la dominante sobre la/s sociedad/es dependiente/s $\mathrm{s}^{4}$.

Existem duas acepções fundamentais de grupo de sociedades que, a seguir, explicaremos.

1) Assim, em um sentido estrito ou próprio, entende-se por grupos de sociedades todo conjunto, mais ou menos amplo de sociedades mercantis que, conservando suas respectivas personalidades jurídicas, encontram-se subordinadas a uma direção econômica unitária e comum.

As especificidades do fenômeno do grupo são, portanto, as seguintes:

a) Sob o ponto de vista econômico, o grupo constituiu uma nova e revolucionária forma de organização da atividade econômica moderna. Ao contrário da

2 CHAMPAUD, Claude. Le pouvoir de concentration de la société para actions. Paris: Libraries Sirey, 1962. p. 197. No mesmo sentido: ÖZTEK, Selçuk. La protection des actionnaires externes dans les groupes de sociétés par une société holding. Lausanne: Lémane, 1982. p. 37; RODIÈRE, René. Droit commercial: groupements commerciaux. 10. ed. Paris: Dalloz, 1980.

3 "La reunión de empresas bajo una dirección única (grupo) es un fenómeno económico que ha tomado en el derecho de todos los Estados fuertemente industrializados un lugar que rebasa, en cuanto a su importancia económica, todas las demás formas de cooperación entre empresas. Esta evolución responde a la tendencia a aumentar de escala. Los grupos presentan, sin embargo, la particularidad de que la dependencia económica de las diversas partes deja subsistir su personalidad jurídica". PEREZ ESCOLAR, Rafael. La sociedad anónima europea. Madrid: Editorial Montecorvo, 1972. p. 344.

4 FERNÁNDEZ DEL POZO, Luis. Grupos horizontales transfronterizos: un primer estudio sobre las sociedades gemelas. In: LAS OPERACIONES societarias de modificación estructural. Valencia: Tirant lo Blanch, 2001. p. 213. empresa tradicional, que se caracterizava por estruturar-se como uma empresa unissocietária, a empresa de grupo se constitui como uma unidade econômica plurissocietária, também chamada de empresa articulada.

b) Por outro lado, sob a perspectiva jurídica, a especificidade do grupo de sociedades radica na oposição latente existente entre a situação de direito (pluralidade jurídica dos entes societários autônomos) e a situação de fato (unidade de atuação econômica, sob um poder de decisão (entral) $)^{5}$.

Dessa forma, os elementos definidores do conceito do grupo de sociedades são a independência jurídica das sociedades agrupadas, assim como a dependência econômica de todas (sociedades filiais) em relação a uma delas (sociedade matriz).

2) Em uma acepção ampla ou imprópria, a expressão grupo de sociedades (Konzern, Groupe de Siciétés, Group of Companies, Gruppo di Società), vem sendo utilizada como termo de referência para o setor da realidade societária que encontra no controle intersocietário e nas relações de coligação entre sociedades seu centro de gravidade.

O direito tradicional das sociedades tem por objetivo a disciplina de constituição, organização e vida da sociedade comercial como entidade estática e isolada. Por sua vez, um direito de grupos de sociedades teria como objeto o estudo e a disciplina da constituição, organização e funcionamento da sociedade como entidade dinâmica e cooperativa. Nesse sentido, se poderia dizer que tal direito surgiria como uma espécie de metadireito das sociedades, de direito de sociedade das sociedades, ou ainda, de um direito das sociedades de segundo grau ${ }^{6}$.

5 WALLACE, Cynthia D. Legal control of the multinational enterprise. Boston; London: Martinus Nijhoff, 1982. p. 43.

6 Para um aprofundamento do estudo da criação de um direito próprio do grupo de sociedades, veja: RONDINONE, Incola. I gruppi di imprese fra diritto comune e diritto speciale. Milano: Giuffrè Eidtore, 1999. p. 3 et seq.; TOMBARI, Umberto. Il grupo di società.Torino: G. Giappichelli Editore, 1997. p. 129 et seq. 


\subsection{Elementos característicos}

Segundo citado anteriormente, dois são os elementos definidores do conceito de grupo de sociedades em sentido estrito: a independência jurídica e a unidade de direção econômica.

1) O primeiro aspecto caracterizador do grupo é a independência jurídica das sociedades integrantes do grupo. As sociedades agrupadas conservam, ainda que sob uma direção econômica unitária, sua personalidade jurídica própria, mantendo tanto sua autonomia patrimonial como organizativa. Ademais, é esse o elemento que nos permite distinguir o grupo de outras técnicas de concentração empresarial, as quais comportam o desaparecimento da individualidade jurídica das entidades envolvidas ${ }^{7}$.

2) O segundo elemento é a unidade de direção econômica das entidades envolvidas.

Ainda que cada uma das sociedades do grupo se mantenha formalmente como um ente jurídico distinto, a verdade é que, sob o ponto de vista da realidade material, as sociedades dependem, em maior ou menor grau, da vontade e interesses do todo econômico, tal como ele seja definido pela sociedade líder do grupo.

Sob essa perspectiva, o grupo de sociedades se constitui como uma unidade econômico-empresarial de segundo grau, em relação com as distintas sociedades individuais que o compõe.

Tal direção econômica unitária se reflete na existência de uma estratégia ou política econômica geral do grupo (group planning process, konzernpolitik), a qual vem definida por um núcleo dirigente (localizado, geralmente, junto à sociedade matriz - group top-management), incidindo sobre os diversos aspectos setoriais do

\footnotetext{
7 Nesse sentido, a fusão, onde a integração econômica das sociedades é acompanhada da extinção da personalidade jurídica de uma das mesmas (fusão-absorção) ou das duas (fusão-criação).

Outro exemplo interessante seria o da não autonomização jurídica das entidades envolvidas, como seria o caso da sucursal (branch, sucursale), onde - ao contrário da filial (subsidiary, filiale), que constitui um sujeito jurídico e nacionalidade distinta da sociedade matriz - representa uma mera divisão ou departamento de uma única sociedade, sem qualquer individualidade jurídica. Nesse sentido: CORREIA, António Ferrer. Manual de direito comercial. Coimbra, 1968-1975, v. 3. p. 147-148.
}

respectivo funcionamento (política mercantil, política de produção, política financeira, política laboral, política de investimentos, política de gestão) e assumindo os distintos graus de integração (que vai desde a total centralização, até as formas mais acentuadas do controle descentralizado $)^{8}$.Ademais, coordena as atividades econômicas particulares das distintas sociedades agrupadas?

\subsection{Terminologia}

O grupo de sociedades se constitui em uma realidade multidisciplinária, cujo impacto legislativo e doutrinal supera, cada vez mais, o mero domínio do direito de sociedades, para projetar-se em outros ramos, principalmente do direito fiscal, o direito da concorrência, o direito do trabalho (laboral), multiplicando-se sua diversidade conceitual e terminológica ${ }^{10}$.

Ante tal diversidade terminológica, manteremos a expressão grupo de sociedades como termo de referência. Desse modo, vamos nos referir às sociedades envolvidas

8 ANTUNES, J. A. Engrácia. Liability of corporate groups: autonomy and control at parent-subsidiary relationships. Kluwer: Deventer, 1993. p. 236 et seq.

9 O elemento da unidade de direção econômica permite distinguir a relação do grupo de outras figuras emergentes do fenômeno de controle intersocietário, como a direção de domínio ou de dependência societária.Esta última consiste na mera detenção por uma sociedade da possibilidade de exercício de influência dominante sobre outra sociedade (em virtude da detenção de um instrumento de domínio, v.g., uma participação majoritária). Não implica no nascimento de uma direção econômica unitária, nem mesmo na formação de uma nova unidade empresarial entre a sociedade dependente e a dominante. A primeira, ao contrario, caracteriza-se pelo exercício efetivo e atual dessa influência dominante, tendente a criar uma direção econômica unitária e comum entre as sociedades e, assim, gerar uma nova unidade empresária plurissocietária. Em outras palavras, a situação da dependência societária representa uma espécie intermediária ou de transição entre a sociedade economicamente autônoma (cuja atividade se orienta por vontade e interesses sociais próprios), e a sociedade agrupada (cuja atividade se encontra virtualmente subordinada a uma vontade e interesses alheios). STORK, Michel. La définition légale du contrôle d'une société en droit français. RevS, Paris, v. 104, n. 3, p. 385-404, 1986.; LA ROSA, Antonio Pavone Controllo e grupo nella fenomenologia dei collegamenti societari. In: IX DIRFAL, 1985. p. 1-23.

${ }^{10}$ JADAUD, Bernard. La vaine recherche d'une définition de groupe en droit français. In: CENTRE DES RECHERCHES ET ÉTUDES DU DROIT DES AFFAIRES (CREDA). Les groupes de sociétés: une politique législative. Paris: Librairies Techniques, 1975. p. 193 et seq. No mesmo sentido: TEUBNER, Gunther. Unitas multiplex: corporate governance in group enterprises. Nomos: Baden-Baden, 1990. p. 91. 
em uma relação de coligação intersocietária, no polo passivo como sociedades filhas (ou equivalente contextual, v.g., sociedade filial). Por outro lado, designaremos como sociedade-mãe a que ocupe o polo ativo da mesma relação de grupo (ou sociedade matriz).

\section{Importância prática: impacto nacional e internacional}

A fisionomia da prática societária atual deixou de ser retratada pela sociedade individual e isolada, passando a refletir o verdadeiro paradigma central do universo econômico e societário, tanto nacional como internacional ${ }^{11}$.

Nos EUA, os cem maiores grupos industriais empregam por volta de $26 \%$ do número total de trabalhadores, realizam $43 \%$ do volume global dos negócios e possuem, sozinhos, quase $50 \%$ da totalidade do ativo patrimonial da indústria norte-americana ${ }^{12}$.

$\mathrm{O}$ mundo da grande empresa norte-americana é o mundo dos grupos de sociedades ${ }^{13}$. A dimensão do poderio dos mesmos é confirmada por sua presença não somente nacional, mas também mundial. Assim, este é o caso das mais de 1.300 filiais do Grupo Mobil Oil, ou
11 "We speak, teach, litigate and legislate about company law. But the predominant reality is not today the company: is the corporate group". Nesse sentido: WEDDERBURN, Lord. Multinationals and the antiquities of company law. ModLR p. 320 1983. No mesmo sentido, encontramos as formulações da Comissão Europeia, em sua Introdução à Proposição de uma 9a Diretiva sobre o Direito dos Grupos de Sociedades, p. 9. Ademais, veja: FREYRIA, Charles. Le droit des groupes sous les feuxs de l'actualité. In: RJC. 1987. p. 121 et seq.

${ }^{12}$ BLAIR, Roger; LANZELLOTTI, Robert. The conglomerate corporation: an antiturst law and economics symposium. Cambridge: Guns \& Hain, 1998. p. 170; BLUMBERG, Philipe. The law of corporate group: problems so parent and subsidiary corporations under statutory law of general application. Boston: Little, 1989. p. 32 et seq.; HERMAN, Edward. Corporate control, corporate power. Cambridge: Cambridge UP, 1981. p. 3 et seq.

Manifestação do impacto do fenômeno constituem as chamadas megassubsidiárias, espécie de holding que se transformou na organização jurídica predominante em vários setores da atividade mercantil norte-americana. Assim, por exemplo, 24 dos 25 maiores bancos mercantis estão constituídos sob a forma de grupo de sociedades liderados por uma megasubsidiary. Nesse sentido: EISENBERG, Melvin. Megasubsidiaries: the effect of corporate structure on corporate control. Harvard law review, v. 84, n. 7, p. 1555 et seq., may 1971.

${ }^{13}$ BLUMBERG, Philipe. The law of corporate group: problems general application. Boston: Little, 1989. p. 9. so parent and subsidiary corporations under statutory law of dos mais de 691 mil trabalhadores do grupo General Motors ${ }^{14}$.

$\mathrm{Na}$ Alemanha, sucessivas investigações demonstram a crescente relevância dos grupos (konzern) no contexto global de sua economia. As investigações realizadas em 1965 concluíram que por volta de 70\% do total de sociedades germânicas haviam deixado de constituir-se em uma sociedade independente, para constituir-se em membro de um grupo de sociedades. Na verdade, as mais recentes pesquisas (1981) sugerem que cerca de $92 \%$ das sociedades anônimas se encontram, de alguma forma, integradas em um grupo de sociedades ${ }^{15}$.

Na França, esta imagem do crescente poder de difusão dos grupos de sociedades foi confirmada por recentes estudos realizados, que têm por base as pesquisas feitas para os maiores grupos franceses.

Assim, grupos como Pèchiney/ Saint-Gobain; Banque de Paris et Pays-Bar; Compagnie Genérale d'Elactricité; etc. constituem estruturas econômico-organizativas que englobam, aproximadamente, 400 empresas cada uma delas ${ }^{16}$. A importância de tais grupos na economia francesa é notável, já que realizam cerca de $50 \%$ do volume de negócios da mesma economia e são responsáveis por $60 \%$ do montante global dos investimentos; $40 \%$ da capacidade laboral; e entre $80 \%$ e $95 \%$ do total da produção industrial do país.

$\mathrm{Na}$ Inglaterra (economia que tem taxa de utilização de técnicas de concentração empresarial superior ao da economia norte-americana ${ }^{17}$ ), existem estudos que demonstram que a medida das sociedades controladas por cada um dos 50 maiores grupos britânicos já era, em 1981, por volta de 230. Ademais, alguns grupos superam as milhares de filiais, como é o caso da British

${ }^{14}$ RADNER, P. The internal economy of larger firms. The Economic Journal, v. 96, Suplem., p. 1-22, 1986.

${ }^{15}$ BÄLZ, Ulrich. Groups of companies: the german approach. Florence, 1986. p. 8 et seq.

${ }^{16}$ CENTRE DES RECHERCHES ET ÉTUDES DU DROIT DES AFFAIRES (CREDA). Les groupes de sociétés: une politique législative. Paris: Libraries Techniques, 1978. p. 13 et seq.

${ }^{17}$ HANNAH, Leslie. The rise of corporate economy. London: Methuen, 1990. p. 215; HANNAH, Leslie; KAY, J. A. Concentration in modern industry. London: Macmillan, 1977. p. 1 et seq. KING, Mervyn. Public policy and corporation. London: Chapman \& Hall, 1977. p. 12 et seq.; PRAIS, S. J. The evolution of giant firms in Britain. $2^{\text {nd }}$. Cambridge: Cambridge UP, 1976. p. 20 et seq. 
Petroleum (com suas 1300 filais), o grupo Unilever (por volta de 1100 filiais), sublinhando-se, como característica fundamental, seu enorme poder econômico ${ }^{18}$ e sua incrível, complexa e intrincada rede de sociedade holding e filiais ${ }^{19}$.

Finalmente, quanto à questão do impacto nacional dos grupos de sociedades, o panorama em outros países europeus parece aproximar-se a esse modelo, como é o caso da Itália ${ }^{20}$, Suíça ${ }^{21}$, Bélgica ${ }^{22}$ etc. Todavia, a afirmação do fenômeno não se limita ao plano das economias nacionais, estando acentuado no plano internacional.

No plano dos fatos, encontramos na empresa multinacional uma expressão particularmente indicativa do protagonismo da técnica do grupo societário.

Em efeito, entre as maiores entidades econômicas do mundo, se encontram 50 Estados e 50 multinacionais. $\mathrm{O}$ volume de negócios das oito maiores multinacionais (Exxon; General Motors; Ford; General Electric; IBM; Chrysler; Texaco; Shell), já em 1971, tinha um faturamento equivalente ao orçamento de seis Estados Membros da CEE (Bélgica, Alemanha, França, Itália, Luxemburgo e Holanda). Além do mais, a progressão do crescimento de

\footnotetext{
${ }^{18}$ Em 1950, os 100 grupos da indústria manufaturada inglesa mais potentes controlavam cerca de $15 \%$ da produção total, sendo o maior grupo o JP Coasts, com 5,5 milhões de libras de ativo patrimonial e 5 mil trabalhadores. Em 1975, os mesmos grupos dominavam quase $50 \%$ da produção nacional, tendo o maior deles (grupo ICI - Industrial Chemical Industries) um patrimônio valorado em 2 bilhões de libras e mais de 200 mil trabalhadores. O grupo ICI constitui o resultado de uma coligação de quatro das maiores empresas britânicas: Nobel Industries, Brunes Mond, British Dyestuffs Corporation y United Alkaly Company, que já constituíam, elas mesmas, grupos societários do setor da indústria química.

${ }^{19}$ HADDEN, Tom. Incide corporate groups. International Journal of the Sociology of Law, p. 274, 1984.

${ }^{20}$ ABADESSA, Pietro: I Gruppi di società nel diritto italian. Bologna: Il Mulino, 1982. p. 103 et seq.; LA ROSA, Antonio Pavone. I gruppi di società: richerca per un studio critic. Bologna: Il Mulino, 1983; PEPE, Giorgio. Il grupo di imprese. Milano: Giuffrè, 1990. p. 6 et seq.

${ }^{21}$ DRUEY, Jean. Company groups in swiss law. In: GROUPS of companies in European Laws. New York:Walter de Gruyter, 1982. p. 131 et seq. Estima-se que cerca de 70\% do total de sociedades suíças, hoje em dia, formam parte, direta ou indiretamente, de um grupo de sociedades.

22 OMMESLAGHE, Pierre van. Les groupes de sociétés et l'expérience du droit belge. In: GROUPS of companies in European Laws. New York: Walter de Gruyter, 1982. p. 59 et seq.; WYMEERSCH, Eddy. The groups of companies in Belgium Law. Brussels: Internal Doc. EEC, 1988. p. 23.
}

tal faturamento é de $10 \%$ ao ano, duas vezes mais que a média de crescimento do PIB mundial ${ }^{23}$.

A chamada empresa multinacional se constitui, sob o ponto de vista jurídico, em um verdadeiro grupo de sociedades, reduzindo-se, desta forma, a respectiva estrutura organizativa às técnicas de coligação e controle de sociedades por sociedades ${ }^{24}$.

No âmbito internacional, houve confirmações e estímulos à importância deste fenômeno, sendo o caso da União Europeia, onde a técnica dos grupos de sociedades foi apontada como o instrumento jurídico principal para o processo de concentração industrial, conducente à instauração de um mercado comum europeu ${ }^{25}$.

Concluindo, qualquer que seja o plano escolhido da realidade econômica moderna (nacional, internacional ou regional), enfrentamos a transformação da função econômica da empresa societária que, exibindo uma tendência irreversível de aniquilação individual a favor da emergência de unidades econômicas multissocietárias,

${ }^{23}$ DUNNING, John; PEARCE, Robert. The world's largest industrial enterprises 1962-1983. Gower: Aldershot, 1985. p. 8.

${ }^{24}$ AHARONI, Yair: On the definition of multinational corporation. In: KAPOOR, Ashok; GRUB, Phillip D. (Ed.). The multinational enterprise in transition: selected readings and essays. Princeton: Darwin Press, 1977. p. 1-54.

${ }^{25} \mathrm{O}$ agrupamento de empresa juridica.ente autônoma sob uma direção unitária representa, desde o ponto de vista econômico, o instrumento mais importante de cooperação interempresarial nos países industrialmente desenvolvidos. Tal processo corresponde a uma tendência, para a formação de unidades maiores, evitando-se os riscos inerentes ao gigantismo. Parece compreensível, pois, que a concentração, por meio dos grupos de sociedades, constitui um mecanismo essencial para a criação de unidades econômicas mais competitivas, devendo ser colocado à disposição das empresas comunitárias, permitindo-lhes realizar a reestruturação e adaptação ao novo espaço econômico comunitário. Nesse sentido: COMISIÓN CEE. Observations préliminaries concernantes les travaux d'harmonosation des législations sur les groupes d'entreprises. 1971. Doc. 548/XIV/71-F.

Nesse mesmo sentido, todavia com data anterior: COMMISSION DES COMMUNAUTES EUROPEÉNNES. La politique industrielle de la communauté: memorandum. Bruxelles, 1970.

A direção que a Comissão apontava no início da década de 70 teve o significado de uma verdadeira profecia. Na realidade, todos os estudos estatísticos levados a efeito, a propósito do impacto das distintas formas de concentração empresarial das empresas no espaço comunitário (fusão, divisão, acordos, práticas combinadas, transferências parciais de ativos) confirmaram o Grupo de Sociedades como instrumento natural da concentração empresarial no espaço comunitário. CAMPOLONGO, Alberto; GRISOLI, Angelo. Le imprese plurinazionali a vocacione europea. Padova: Cedam, 1972. p. 123 et seq. 
estaria passando da era do átomo para a era da molécula do direito das sociedades ${ }^{26}$.

\section{A efeito de conclusão: causas do recurso a esta figura}

O grupo de sociedades vem assumindo o protótipo da empresa moderna, caracterizado como a técnica econômica mais importante e significativa do fenômeno da concentração empresarial ${ }^{27}$. Certamente, tal fato não ocorreu por acaso.

A verdade é que existem muitas vantagens que explicam o recurso, por parte da empresa moderna, ao grupo de sociedades como técnica revolucionária da organização de sua atividade econômica.

\subsection{Vantagens econômicas}

Por um lado, a técnica do grupo de sociedades se adapta a todo tipo de necessidades de concentração das empresas.

Ao reunir distintas sociedades em uma unidade econômica, financeira e mercantil comum, permanecendo as mesmas com independência patrimonial e jurídica, a técnica do grupo de sociedades permite as operações de integração vertical ${ }^{28}$, assim como a integração horizontal $^{29}$ e, finalmente, a integração conglomerada ${ }^{30},{ }^{31}$. Por

${ }^{26}$ RODIĖRE, René. Le droit des rociétés dans ses rapports avec la concentration. Bruxelles: Collection Études, 1967. p. 53; RODIÈRE, René. La protection des minorités dans les groupes de sociétés. RevS , p. 243, 1970.

${ }^{27}$ ÖZTEK, Selçuk. La protection des actionnaires externes dans les groupes de sociétés par une société holding. Lausanne: Lémane, 1982. p. 37.

${ }^{28}$ Integração vertical - assegura à sociedade matriz do grupo a certeza de que jamais será privada de suas fontes de abastecimento, ademais de abrir boas perspectivas de maximização da capacidade produtiva, permitindo obter maior aproveitamento e exploração das atividades lucrativas que seriam secundárias no seio de uma empresa única.

${ }^{29}$ Integração horizontal - assegura à sociedade matriz uma redução dos custos fixos, bem como um crescimento de seu poder no mercado, resultando importantes economias de escala.

${ }^{30}$ Integração conglomerada - permite à sociedade matriz exercer um domínio sobre as filiais, atuando nos mercados nacionais e para produtos diversificados, procedendo a combinação de uma política de diversificação do risco empresarial, bem como a implantação internacional capaz de assegurar a sobrevivência no âmbito da economia global.

${ }^{31}$ BRESSY, Maurice; RICHOUX, Pilles. Les regroupements d'enterprise: la concentration sans fusion: économie et humanisme. Paris, 1980. p. 24. outro lado, é uma técnica à qual todas as grandes sociedades têm que recorrer, evitando-se, assim, o risco do gigantismo.

Dessa forma, adota-se, como paradigma econômico, que a empresa não pode crescer indefinidamente, sem sofrer graves deseconomias de dimensão, baseada em uma progressiva redução da respectiva eficácia econômica e de um agravamento de sua rigidez organizativa ${ }^{32}$.

A estrutura do grupo permite evitar esses riscos derivados da concentração, sem que, também, tenha que renunciar às suas vantagens. Ela permite realizar uma descentralização na concentração ${ }^{33}$.

1) Assim, por meio da divisão da atividade econômica unitária por um agregado de entidades societárias, alcança-se uma gestão racional, obtendo-se uma especialização funcional e uma descentralização organizativa interna, sem renunciar a unidade dos objetivos estratégicos ou do controle dos ganhos gerais.

2) Por outro lado, trata-se de uma técnica que permite criar, para a organização da atividade da empresa, uma estrutura maleável e flexível. Na realidade, no grupo de sociedades não estamos vinculados a uma ou duas formas legais (como ocorreria na fusão), mas a uma multiplicidade de formas, tantas quanto a imaginação do empresário tenha capacidade para criar.

A partir daí, afirma-se que o grupo de sociedades qualifica todas as demais técnicas da concentração empresarial: a) às rescisões sucedem as transferências de ativos; b) as designações de administradores comuns são substituídas pelo cruzamento de participações sociais; c) os acordos de votos (pelos quais se opera a distribuição de influências e poderes dentro das filiais) são substituídos pelas cessões ou aquisições de ações; d) as próprias sociedades-mães de diferentes grupos podem

${ }^{32}$ PENROASE, Edith. The theory of the growth of the firm. Oxford: Blackwell, 1980. p. 261. Se há economias de escala que resultam da maior dimensão da empresa, também há deseconomias de escala que neutralizam as vantagens da grande dimensão. Podem surgir dificuldades de organização, problemas de coordenação, insensibilidade de gestão, excessos burocráticos. Nesse sentido, veja: CARREIRA, Medina. Concentração de empresas e grupos de sociedades: aspectos histórico-económicos e jurídicos. Lisboa: IESF, 1992. p. 28.

${ }^{33}$ JACQUEMIN, Alexis. Le group de société: décentralisation dans la concentration. In: LES GROUPES de sociétés. Haya: Martinus Nijhoff, 1972. p. 27 et seq. 
associar-se, por meio da criação de filiais comuns (joint ventures). Além disso, e) o movimento de constituição dos grupos de sociedades começa a chegar a seu ponto máximo, atualmente sendo visível a constituição de grupos de sociedades que se agrupam em entidades ainda mais potentes ${ }^{34}$. Assim, afirma-se graficamente que a vida dos grupos de sociedade é um verdadeiro carrossel de técnicas jurídicas ${ }^{35}$.

3) Ademais, o grupo de sociedades é um instrumento suficientemente flexível para permitir constantes reajustes ou adaptações de estratégias do próprio grupo às condições do meio econômico de seu entorno. Ao contrário do que ocorre com as técnicas de concentração mais rígidas (v.g. a fusão), é relativamente fácil para a sociedade matriz separar-se de uma filial do grupo. Quando se trata de um grupo baseado em uma participação de capital ou por laços contratuais, os custos econômicos e institucionais da separação serão sempre menores que no caso do desmembramento de uma sociedade única ${ }^{36}$.

4) Finalmente, um aspecto a destacar seria o de que o grupo permite a empresa moderna adaptar-se à progressiva substituição do modelo horizontal do mercado (baseado no mecanismo automático de preços) para um modelo vertical de organização hierárquica, como mecanismo alternativo de coordenação da atividade econômica. Com efeito, constatado que o mecanismo de preços não funciona de forma neutra sob o ponto de vista da eficácia econômica ${ }^{37}$, a empresa desenvolve mecanismos para transformar tais relações negociáveis em relações internas, sujeitando-as à coordenação da respectiva estrutura hierárquica. Desse modo, a empresa internaliza o próprio

\footnotetext{
${ }^{34}$ Veja o recente exemplo que foi a aquisição dos grupos automotivos Alfa Romeo e Lancia, cada um possuidor de, aproximadamente, 300 filiais, pelo grupo rival Fiat.

${ }^{35}$ CHAMPAUD, Claude. Le pouvoir de concentration de la société para actions. Paris: Libraries Sirey, 1962. p. 207.

${ }^{36}$ COMMISSION DES COMMUNAUTES EUROPEÉNNES. Introduction à la proposition d'une 9 ème directive surle droit des groupes de sociétés: Document Davignon. Bruxelles, 1 out. 1980. p. 32.

${ }^{37}$ As transações realizadas pela empresa no mercado aberto implicam custos, advindos da necessidade de negociação, conclusão e supervisão dos contratos separados para cada relação específica, da aleatoriedade associada ao oportunismo dos agentes econômicos etc. (os chamados transactions costs).
}

mercado, distanciando-se dos custos inerentes às transações no mercado livres ${ }^{38}$.

\subsection{Vantagens financeiras}

A técnica do grupo de sociedades traz, consigo, inegáveis vantagens financeiras.

De fato, ao contrário do que ocorre com a fusão e as transferências de ativos (que implicam na mobilização de um grande volume de ativos financeiros), os grupos constituem um grande atrativo para os operadores econômicos, uma vez que são uma técnica que permite assegurar o controle de uma enorme massa de capitais e a direção econômica de numerosas empresas societárias individuais, com um investimento inicial de capital reduzido ${ }^{39}$.

Assim, com um reduzido investimento inicial de capital, poderá a sociedade obter o domínio de uma

${ }^{38} \mathrm{Na}$ concorrência real entre estes dois mecanismos de coordenação da atividade econômica, mercado e hierarquia DAEMZ, Herman. The rise of modern industrial enterprise. Leiden: Nijhoff, 1980. p. 205, não restam dúvidas sobre a primazia do segundo. A mão invisível do mercado aberto e horizontal, forjada pelos economistas clássicos, vem sendo substituída pela mão visível das organizações econômicas gigantescas que, por meio de uma complexa rede hierárquica de controle e coligações interempresariais, eliminam em seu benefício a dúvida e os custos inerentes ao livre jogo das forças do mercado, coordenando a atividade econômica das unidades constituintes.CHANDLER, Alfre; DAEMZ, Herman. Managerial hierarchies: comparative perspectives on the rise of the modern industrial enterprise. New York: Atheneum, 1981. p. 11; CHANDLER, A. The visible hand: the managerial revolution in american business. Cambridge: Havard UP, 1977. p. 3. Daí a necessidade do controle de tais grupos societários pelo direito da concorrência.

${ }^{39} \mathrm{Se}$, por exemplo, uma sociedade com capital social de 10.000 decide empregar o respectivo patrimônio na aquisição de outras sociedades com idêntico capital social, o sócio que possui a metade do capital da primeira sociedade passará a controlar, de fato, com uma inversão de somente 5000, um total de capitais de cerca de 30000 , bem como três massas patrimoniais diferentes (como é sabido, cifras inferiores são normalmente tidas como idôneas para permitir o controle da sociedade, na ordem de $30 \%, 15 \%$ e, até mesmo, no caso particular de certas sociedades norte-americanas, v.g., General Motors Corporation, de apenas $2 \%$ ).

Se as sociedades participantes tiveram, elas próprias, participação em outras sociedades, então o total patrimonial aumentará ainda mais, bem como o conjunto de sociedades subordinadas aos interesses da política econômica geral traçada pelo sócio controlador. 
enorme massa de capital e patrimônios vinculados a uma direção econômica comum ${ }^{40},{ }^{41}$.

\subsection{Vantagens jurídicas}

Várias são as vantagens jurídicas que derivam da constituição dos grupos de sociedades.

1) Desde logo, enquanto o grupo constitui, por definição, uma unidade econômica cujas células conservam a respectiva autonomia jurídica e patrimonial, oferece-se à respectiva sociedade líder uma verdadeira divisão dos riscos de exploração empresarial, já que cada sociedade agrupada, em princípio, responderá pelas dívidas somente no limite de seu patrimônio.

A manutenção da personalidade jurídica das sociedades do grupo, assim como a consequente limitação das responsabilidades patrimoniais aos respectivos passivos, assegura, em caso de dificuldades, catástrofes financeiras ou quebra de uma delas, às demais sociedades, a irresponsabilidade pelos débitos desta para com os respectivos credores. Isso é especialmente interessante para a sociedade matriz que, não obstante o controle das filiais e dos benefícios que tenha com elas, está protegido contra eventuais perdas.

Como se vê, esse efeito de divisão dos riscos empresariais e sua externalização para os terceiros, proveniente da conservação da autonomia jurídica das sociedades agrupadas, efeito este proveniente da conservação da autonomia jurídica das sociedades agrupadas, é um efeito que somente a técnica do grupo de sociedades pode produzir ${ }^{42}$.

${ }^{40}$ CHEVALIER, Alain; VIGNERON, Philippe. La gestion financière des groupes. Paris: Dunod; Bordas, 1984. p. 13 et seq.

${ }^{41}$ Retratado no caso dos chamados grupos industriais de participação piramidal, como os grupos IBM, Unilever, e Rank Xerox.

${ }^{42}$ Sem dúvida este efeito da divisão e externalização dos riscos da atividade da empresa do grupo começa a sofrer importantes correções, seja no âmbito legislativo, seja no âmbito jurisprudencial, seja no âmbito da própria doutrina, onde se questiona o acerto do tradicional dogma da responsabilidade limitada dos sócios das sociedades de capitais no domínio das pessoas coletivas e, em particular, das sociedades mercantis. Para uma visão do direito comparado na matéria, veja: ANTUNES, J. A. Engrácia. Liability of corporate groups: autonomy and control at parent-subsidiary relationships. Kluwer: Deventer, 1993. p. 170 et seq.

Importante sublinhar a existência da teoria da disregard doctrine, a qual propugna pela quebra da personalidade jurídica da sociedade obrigada direta e a assunção das responsabilidades por todos os membros do grupo.
2) Por outro lado, a constituição de um grupo traz apreciáveis vantagens jurídico-fiscais:

a) Primeiro, porque sua formação constitui, geralmente, objeto de benefícios fiscais diretos, na medida em que os legisladores, de um ou mais Estados, costumam incentivar a multiplicação dos grupos empresarias fortes e competitivos ${ }^{43}$.

b) Segundo, porque sua organização se conforma como meio eficaz contra a progressão dos tributos no plano do direito tributário interno (nacional). Múltiplas sociedades pequenas são tributadas a uma alíquota menor que uma sociedade grande, para um idêntico fato gerador de tributação, o que gera benefícios e economias.

c) Terceiro, porque os mecanismos de formação da empresa de grupo (principalmente a aquisição de participações sociais) são muito mais favoráveis que outros mecanismos alternativos, tais como a fusão, a divisão e o arrendamento. Enquanto estas estão rodeadas de operações complexas, todas tributáveis, os grupos (principalmente os constituídos sob participações sociais) não estão envolvidos em formalidades, estando mais levemente tributados ${ }^{44}$.

\footnotetext{
${ }^{43}$ Veja, v.g., o regime fiscal aplicado as sociedades holding no direito portugués (DL no 495/88, del 30 de diciembre de 1988). Assim, as sociedades holding constituem o vértice hierárquico de um tipo de grupo de sociedades caracterizado pelo fato de que a sociedade-mãe possui um objeto puramente financeiro. Sua atividade está circunscrita na gestão estratégica da carteira de participações sociais detidas nas distintas sociedades componentes do grupo.

À semelhança do que ocorre em outras legislações que regulam a matéria de idêntica forma ( $v . g$., a norte-americana), foi necessário consagrar em seu favor os benefícios fiscais (art. $7^{\circ}$ ), sem os quais tais sociedades teriam viabilidade duvidosa ou pouco interesse prático. Sobre o regime fiscal desse tipo de sociedades, veja: GUIMARÃES, Vasco. Sobre a tributação das holding. O Fisco, Lisboa, n. 19, p. 12 et seq.1990.; OLIVEIRA, Jorge. O regime fiscal das sociedades holding. O Fisco, Lisboa, n. 6, p. 13 et seq. 1989.; BARALO, Jean. Le holding: régime juridique et fiscal. Paris: Dalloz, 1981. p. 15 et seq.; LIBONATI, Berardino. Holding e investment trusts. Milano: Giuffré, 1977. p 11 et seq.

${ }^{44}$ GORÉ, François; JADAUD, Bernard. Droit fiscal des affaires. Paris: Dalloz, 1984. p. 69 et seq.
} 
d) Quarto, porque a habitual implantação nos paraísos fiscais permite à sociedade matriz canalizar os ganhos globais do grupo para territórios onde, a priori, terá uma atribuição muito inferior àquela que resultaria da submissão dos dividendos realizados por cada uma das sociedades por ela dominadas aos respectivos regimes fiscais nacionais ${ }^{45}$.

3) O grupo é também uma técnica com valor jurídicoconcorrencial e jurídico-laboral.

De fato, trata-se de uma técnica para a qual as sociedades recorrem crescentemente, não somente com a esperança de tornar opacas certas relações, acordos tácitos ou práticas de não concorrência ${ }^{46}$, mas também para tentar escapar à aplicação de normas jurídico-laborais ${ }^{47}$.

4) Finalmente, no caso da Europa, os grupos são considerados como agentes privilegiados da integração europeia e da criação de um espaço comum, dada sua extraordinária facilidade de adaptação aos imperativos resultantes do comércio mundial e sua vocação internacional ${ }^{48}$.

${ }^{45}$ Pensa-se, por exemplo, no enorme número de holdings que tem sua sede em países como Luxemburgo ou Suíça, os quais hospedam sociedades-mãe de muitos grupos multinacionais.

${ }^{46}$ Para uma primeira análise da evolução sofrida pela jurisprudência comunitária em matéria de aplicação das normas de concorrência ao fenômeno dos grupos, veja: $\mathrm{MACH}$, Oliver. L'Entreprise et les groupes de sociétés en droit européen de la concurrente. Genève: George, 1974. p. 23; CORDEIRO, António Robalo. As coligações de empresas e os direitos português e comunitário da concorrência. In: RDES, 29. Lisboa, 1987. p. 81 et al.

${ }^{47}$ Seria o caso de uma mesma atividade econômica, exercida sob uma única autoridade, vir a ser repartida artificialmente entre duas ou mais sociedades, com a intenção da divisão dos trabalhadores por ambas. A ideia aí seria a de que a divisão permite que não se alcance o número mínimo de trabalhadores por cada sociedade, já que a lei poderia impor a constituição de determinados órgãos representativos da categoria laboral (v.g., el comité d'entreprise francês).

Seria, ainda, o caso dos trabalhadores que estarão sempre empregados pela sociedade que tenha um convenio coletivo com menos benefícios para eles. GUYON, Yves. Droit des affaires. Paris: Economique, 1988. p. 592; DAVIES, P. Labour law and multinational groups of companies. In: GROUPS of companies in European Law. New York: Walter de Gruyter, 1982. p. 208 et seq.; GALGANO, Francesco. Collegamento di società e rapporti di lavoro. Milano: Giuffrè, 1988. p. 33 et seq.

${ }^{48}$ GUYON, Yves. Examen critique des projects européens en matière de groupes de sociétés. In: GROUPS of companies in European Law. New York :Walter de Gruyter, 1982. p. 155 et seq.

\section{Referências}

ABADESSA, Pietro: I Gruppi di società nel diritto italian. Bologna: Il Mulino, 1982.

AHARONI, Yair: On the definition of multinational corporation. In: KAPOOR, Ashok; GRUB, Phillip D. (Ed.). The multinational enterprise in transition: selected readings and essays. Princeton: Darwin Press, 1977.

ANTUNES, J. A. Engrácia. Liability of corporate groups: autonomy and control at parent-subsidiary relationships. Kluwer: Deventer, 1993.

BÄLZ, Ulrich. Groups of companies: the german approach. Florence, 1986.

BARALO, Jean. Le holding: régime juridique et fiscal. Paris: Dalloz, 1981.

BLAIR, Roger; LANZELLOTTI, Robert. The conglomerate corporation: an antiturst law and economics symposium. Cambridge: Guns \& Hain, 1998.

BLUMBERG, Philipe. The law of corporate group: problems so parent and subsidiary corporations under statutory law of general application. Boston: Little, 1989.

BRESSY, Maurice; RICHOUX, Pilles. Les regroupements d'enterprise: la concentration sans fusion: économie et humanisme. Paris, 1980.

CAMPOLONGO, Alberto; GRISOLI, Angelo. Le imprese plurinazionali a vocacione europea. Padova: Cedam, 1972.

CARREIRA, Medina. Concentração de empresas e grupos de sociedades: aspectos histórico-económicos e jurídicos. Lisboa: IESF, 1992.

CHAMPAUD, Claude. Le pouvoir de concentration de la société para actions. Paris: Libraries Sirey, 1962.

CHANDLER, A. The visible hand: the managerial revolution in american business. Cambridge: Havard UP, 1977.

CHANDLER, Alfre; DAEMZ, Herman. Managerial hierarchies: comparative perspectives on the rise of the modern industrial enterprise. New York: Atheneum, 1981.

CHEVALIER, Alain; VIGNERON, Philippe. La gestion financière des groupes. Paris: Dunod; Bordas, 1984.

COMMISSION DES COMMUNAUTES EUROPEÉNNES. La politique industrielle de la communauté: memorandum. Bruxelles, 1970.

COMMISSION DES COMMUNAUTES EUROPEÉNNES. Introduction à la proposition d'une 9 ème directive surle droit des groupes de sociétés: Document Davignon. Bruxelles, 1 out. 1980. 
COMISIÓN CEE. Observations préliminaries concernantes les travaux d'harmonosation des législations sur les groupes d'entreprises, 1971. Doc. 548/XIV/71-F.

CORDEIRO, António Robalo. As coligações de empresas e os direitos português e comunitário da concorrência. In: RDES, 29. Lisboa, 1987.

CORREIA, António Ferrer. Manual de direito comercial. Coimbra, 1968 - 1975, v. 3.

CENTRE DES RECHERCHES ET ÉTUDES DU DROIT DES AFFAIRES (CREDA). Les groupes de sociétés: une politique législative. Paris: Libraries Techniques, 1978.

DAEMZ, Herman. The rise of modern industrial enterprise. Leiden: Nijhoff, 1980.

DAVIES, P. Labour law and multinational groups of companies. In: GROUPS of companies in European Law. New York: Walter de Gruyter, 1982.

DRUEY, Jean. Company groups in swiss law. In: GROUPS of companies in European Laws. New York:Walter de Gruyter, 1982.

DUNNING, John; PEARCE, Robert. The world 's largest industrial enterprises 1962-1983. Gower: Aldershot, 1985.

EISENBERG, Melvin. Megasubsidiaries: the effect of corporate structure on corporate control. Harvard law review, v. 84, n. 7, may 1971.

FERNÁNDEZ DEL POZO, Luis. Grupos horizontales transfronterizos: un primer estudio sobre las sociedades gemelas. In: LAS OPERACIONES societarias de modificación estructural. Valencia: Tirant lo Blanch, 2001.

FREYRIA, Charles. Le droit des groupes sous les feuxs de l'actualité. In: RJC, 1987.

GALGANO, Francesco. Collegamento di società e rapporti di lavoro. Milano: Giuffrè, 1988.

GORÉ, François; JADAUD, Bernard. Droit fiscal des affaires. Paris: Dalloz, 1984.

GUIMARÃES, Vasco. Sobre a tributação das holding. O Fisco, Lisboa, n. 19, 1990.

GUYON, Yves. Droit des affaires. Paris: Economique, 1988.

GUYON, Yves. Examen critique des projects européens en matière de groupes de sociétés. In: GROUPS of companies in European Law. New York :Walter de Gruyter, 1982.

HADDEN, Tom. Incide corporate groups. International Journal of the Sociology of Law, 1984.
HANNAH, Leslie. The rise of corporate economy. London: Methuen, 1990.

HANNAH, Leslie; KAY, J. A. Concentration in modern industry. London: Macmillan, 1977.

HERMAN, Edward. Corporate control, corporate power. Cambridge: Cambridge UP, 1981.

JACQUEMIN, Alexis. Le group de société: décentralisation dans la concentration. In: LES GROUPES de sociétés. Haya: Martinus Nijhoff, 1972.

JADAUD, Bernard. La vaine recherche d'une définition de groupe en droit français. In: CENTRE DES RECHERCHES ET ÉTUDES DU DROIT DES AFFAIRES (CREDA). Les groupes de sociétés: une politique législative. Paris: Librairies Techniques, 1975.

KING, Mervyn. Public policy and corporation. London: Chapman \& Hall, 1977.

LA ROSA, Antonio Pavone Controllo e grupo nella fenomenologia dei collegamenti societari. In: IX DIRFAL, 1985.

LA ROSA, Antonio Pavone. I gruppi di società: richerca per un studio critic. Bologna: Il Mulino, 1983.

LIBONATI, Berardino. Holding e investment trusts. Milano: Giuffré, 1977.

MACH, Oliver. L 'Entreprise et les groupes de sociétés en droit européen de la concurrente. Genève: George, 1974.

OLIVEIRA, Jorge. O regime fiscal das sociedades holding. $O$ Fisco, Lisboa, n. 6, 1989.

OMMESLAGHE, Pierre van. Les groupes de sociétés et l'expérience du droit belge. In: GROUPS of companies in European Laws. New York: Walter de Gruyter, 1982.

ÖZTEK, Selçuk. La protection des actionnaires externes dans les groupes de sociétés par une société holding. Lausanne: Lémane, 1982.

PENROASE, Edith. The theory of the growth of the firm. Oxford: Blackwell, 1980.

PEPE, Giorgio. Il grupo di imprese. Milano: Giuffrè, 1990.

PEREZ ESCOLAR, Rafael. La sociedad anónima europea. Madrid: Editorial Montecorvo, 1972.

PRAIS, S. J. The evolution of giant firms in Britain. $2^{\text {nd }}$ ed. Cambridge: Cambridge UP, 1976.

RADNER, P. The internal economy of larger firms. The Economic Journal, v. 96, Suplem., 1986. 
RODIÈRE, René. Droit commercial: groupements commerciaux. 10. ed. Paris: Dalloz, 1980.

RODIÈRE, René. La protection des minorités dans les groupes de sociétés. RevS ,197

RODIÈRE, René. Le droit des rociétés dans ses rapports avec la concentration. Bruxelles: Collection Études, 1967.

RONDINONE, Incola. I gruppi di imprese fra diritto comune e diritto speciale. Milano: Giuffrè Eidtore, 1999.

STORK, Michel. La définition légale du contrôle d'une société en droit français. RevS , Paris, v. 104, n. 3, p. 385-404, 1986.
TEUBNER, Gunther. Unitas multiplex: corporate governance in group enterprises. Nomos: Baden-Baden, 1990.

TOMBARI, Umberto. Il grupo di società.Torino: G. Giappichelli Editore, 1997.

WALLACE, Cynthia D. Legal control of the multinational enterprise. Boston; London: Martinus Nijhoff, 1982.

WEDDERBURN, Lord. Multinationals and the antiquities of company law. ModLR 1983.

WYMEERSCH, Eddy. The groups of companies in Belgium Law. Brussels: Internal Doc. EEC, 1988. 
Para publicar na Revista de Direito Internacional, acesse 0 endereço eletrônico www.publicacoesacademicas.uniceub.br. Observe as normas de publicação, para facilitar e agilizar o trabalho de edição. 